Editor's Note: These short reviews of recent JNeurosci articles, written exclusively by students or postdoctoral fellows, summarize the important findings of the paper and provide additional insight and commentary. If the authors of the highlighted article have written a response to the Journal Club, the response can be found by viewing the Journal Club at www.jneurosci.org. For more information on the format, review process, and purpose of Journal Club articles, please see http://jneurosci.org/content/ preparing-manuscript\#journalclub.

\title{
Gpr17, a Player in Lysolecithin-Induced Demyelination, Oligodendrocyte Survival, and Differentiation
}

\author{
๑Maryam Sadat Seyedsadr ${ }^{1,2}$ and $\odot$ Benjamin Victor Ineichen ${ }^{2}$ \\ ${ }^{1}$ Department of Physiology, Faculty of Medical Sciences, Tarbiat Modares University, Tehran, Islamic Republic of Iran, and ${ }^{2}$ Brain Research Institute, \\ University of Zurich, CH-8057 Zurich, Switzerland \\ Review of Ou et al.
}

Multiple sclerosis (MS) is a neuro-inflammatory disease of the CNS. The symptoms start with the entrance of immune cells to the CNS, which causes inflammation, demyelination, and axonal degeneration. After demyelination, oligodendrocyte progenitor cells (OPCs) become active, proliferate, and differentiate to oligodendrocytes, which can regenerate the myelin sheaths (remyelination). Eventually, remyelination fails to reverse demyelination, leading to chronic demyelination, persistent conduction failure along axons, and axonal degeneration due to lack of trophic support from the myelin sheath. This chronic demyelination is a hallmark of the progressive MS disease stage (Mahad et al., 2015), and it is the main cause of permanent and progressive disability in MS patients. The genetic basis underlying the complex cascade of demyelination, remyelination, and the

Received Dec. 9, 2016; revised Jan. 21, 2017; accepted Jan. 27, 2017.

M.S.S. was supported by Iranian Ministry of Science, Research and Technology, Cognitive Sciences and Technologies Council of Iran, and MSIF's Du Pré Grant. B.V.I. was supported by the Swiss MS Society, the HartmannMüller Foundation, Zurich, the Desirée-and-Niels-Yde Foundation, and Swiss National Science Foundation MD-PhD Fellowship 323530_151488. We thank Prof. Martin Schwab, Prof. Mohammad Javan, and Mea Holm for critical inputs on the manuscript.

The authors declare no competing financial interests.

Correspondence should be addressed to Maryam Sadat Seyedsadr,

Brain Research Institute, Winterthurerstrasse 190, University of Zurich, CH-8057 Zürich, Switzerland. E-mail: m.s.seyedsadr@gmail.com.

DOI:10.1523/JNEUROSCI.3778-16.2017

Copyright $\odot 2017$ the authors $\quad 0270-6474 / 17 / 372273-03 \$ 15.00 / 0$ progression to chronic demyelination is still marginally defined.

Because most therapeutic strategies for MS target the immune system and are less effective or ineffective in the chronic progressive phase of the disease (Lassmann, 2013), preservation of oligodendrocytes or increasing their remyelinating potential is a crucial target for novel MS treatments. A first step toward developing potential promyelinating therapies is to identify genes whose expression is affected during demyelination and subsequent remyelination. Ou et al. (2016) used this approach and reported their findings in a study recently published in The Journal of Neuroscience.

The authors used chromatin immunoprecipitation and sequencing to identify transcriptional changes accompanying lysolecithin-induced oligodendrocyte cell death in cultures. Lysolecithin is toxic to oligodendrocytes, and it is often used to induce oligodendrocyte cell death in vitro. Lysolecithin-treated oligodendrocytes showed numerous transcriptional alterations, including upregulation of Olig2. Because Olig2 is an important transcription factor for oligodendrocyte lineage cells ( $\mathrm{Lu}$ et al., 2000; Zhou et al., 2000), Ou et al. (2016) focused on this molecule and its potential downstream targets in subsequent experiments.

One downstream effect of Olig2 upregulation was transcriptional activation of G-protein-coupled receptor 17 (Gpr17).
Gpr17 was previously found to be expressed in OPCs and premature oligodendrocytes (Fumagalli et al., 2011), and it has been proposed to have a role in OPC differentiation and developmental myelination (Chen et al., 2009; Simon et al., 2016; Viganò et al., 2016). These studies showed that Gpr17 inhibits OPC differentiation in vitro and delays myelination during development in vivo. Gpr17 is also upregulated in MS plaques and in animal models of stroke and spinal cord injury (SCI) (Lecca et al., 2008; Ceruti et al., 2009; Chen et al., 2009), and Gpr17 inhibition was shown to reduce tissue damage in these animal models (Lecca et al., 2008; Ceruti et al., 2009). Thus, Gpr17 has received the nickname "damage sensor." The role of Gpr17 in remyelination has never been assessed, but given its role in CNS insult, Ou et al. (2016) hypothesized that it is involved in lysolecithin-induced gliotoxicity.

The authors confirmed the involvement of Gpr17 in oligodendrocyte cytotoxicity following lysolecithin treatment in vitro. Overexpression or pharmacological activation of Gpr17 using MDL29951 decreased survival of oligodendrocytes. In addition, applying Gpr17 sh-RNA or pharmacologically inhibiting it with pranlukast increased oligodendrocyte survival after lysolecithin treatment. These experiments provide evidence that lysolecithin-induced oligodendrocyte death is mediated by upregulation of Olig2 and Gpr17. 


\section{Lysolecithin}

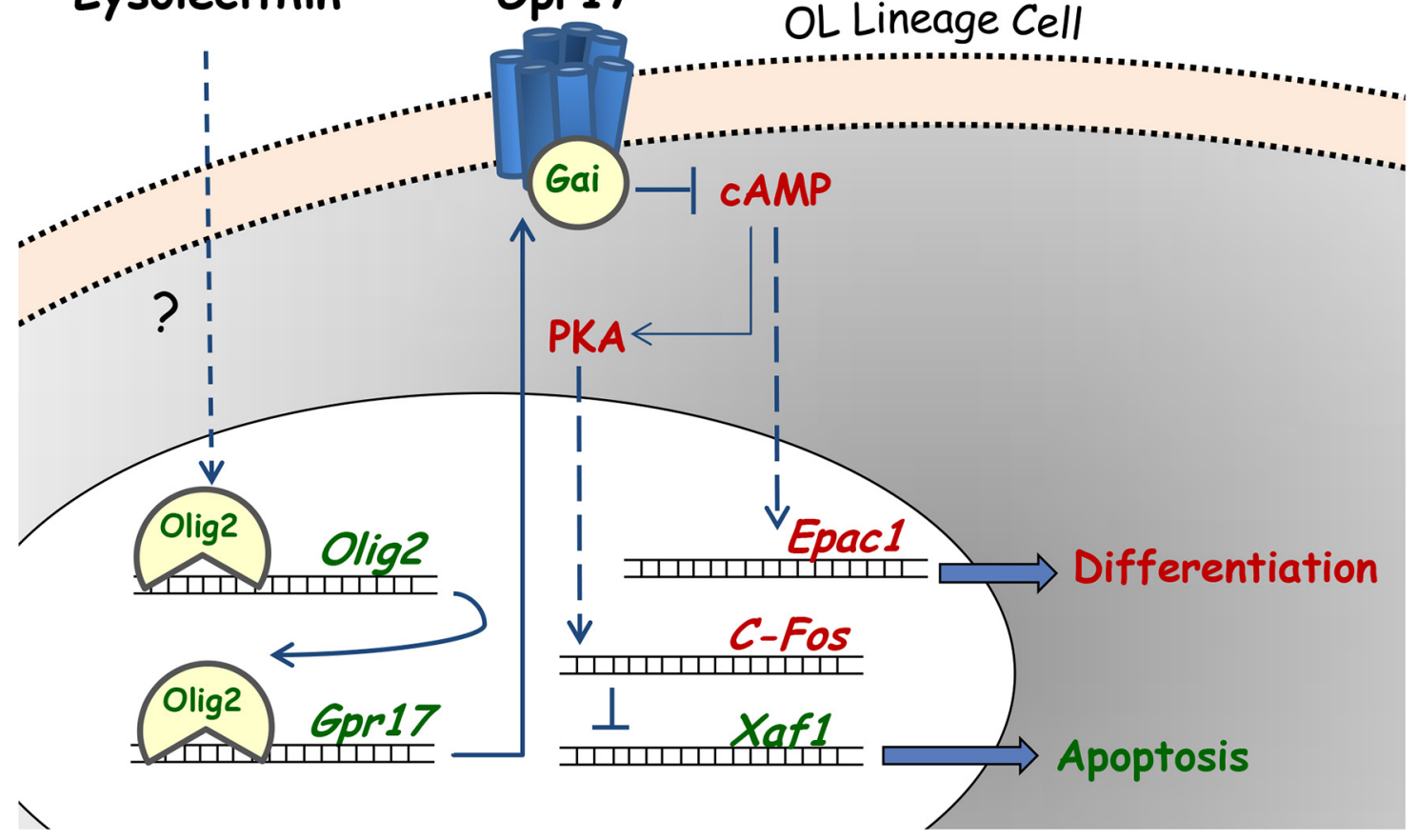

Figure 1. Gpr17 signaling pathway following lysolecithin insult. The signaling pathway tracked in primary rat OPCs and differentiated oligodendrocytes (labeled as OL lineage cell) in vitro. Lysolecithin treatment increases Olig2 expression in oligodendrocytes via an unknown mechanism. Following this, Olig2 upregulates Gpr17 expression. Gpr17 activation leads to reduced intracellular cAMP levels with subsequent decrease in PKA activation. This in turn affects the expression of several downstream genes, including downregulation of $c-$ Fos, which results in upregulation of Xaf1, a proapoptotic gene that leads to oligodendrocyte apoptosis. Furthermore, Epac1 is downregulated as a result of this signaling cascade, which leads to an inhibition of oligodendrocyte differentiation. Green represents the factors that are induced in this process. Red represents the elements that are inhibited.

Next, the authors addressed which downstream genes are responsible for the increased oligodendrocyte cell death. First, they examined genes involved in apoptosis. It has been shown before that Gpr17 mediates its downstream signaling through the Gi $\alpha$ subunit (G $\alpha \mathrm{i})$, which inhibits cAMP production and, subsequently, the activity of protein kinase A (PKA) (Simon et al., 2016). Examining expression of different proapoptotic genes in Gpr17-deficient mice revealed that lysolecithin-induced upregulation of Gpr17 mediated PKA inhibition, which led to an upregulation of Xafl gene. This finally led to oligodendrocyte cytotoxicity. This upregulation of Xaf1 was mediated by a downregulation of $c$-Fos (Fig. 1), a pro-oncogene transcription factor that is regulated by PKA. Furthermore, Ou et al. (2016) showed that the expression of Xaf1 is mediated specifically through $c$-Fos and not other regulatory factors.

In addition to genes involved in apoptosis, Ou et al. (2016) examined expression of Epac (exchange protein directly activated by cAMP), a gene involved in OPC differentiation. They chose this gene because a recent study reported that Gpr17 activation negatively regulated OPC differentiation by decreasing cAMP, which led to a downregulation of Epac (Simon et al., 2016).
In line with this, Ou et al. (2016) showed that Gpr17 activation mediated cAMP reduction and Epacl downregulation, which culminated in inhibition of OPC differentiation in vitro, as shown by decreased expression of $M B P$, which encodes a protein needed for compaction of myelin sheaths during myelin formation/remyelination.

These in vitro results were confirmed and extended in vivo by assessing the role of Gpr17 in developmental myelination and remyelination after lysolecithin treatment in the corpus callosum of mice deficient in Gpr17 or wild-type mice treated with the Gpr17 inhibitor pranlukast. At postnatal day 0, Gpr17-deficient mice showed precocious myelination, as indicated by immunostaining of MBP. Injection of lysolecithin caused local demyelination and subsequent

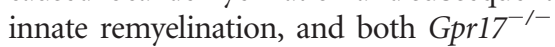
and wild-type mice treated with pranlukast showed enhanced remyelination compared with wild-type untreated mice, as shown by $\mathrm{MBP}$ and $\mathrm{CC} 1$ immunostaining (a marker for oligodendrocytes). However, MBP staining was not quantified, and CC1 is expressed not only in myelinating oligodendrocytes but also in premyelinating oligodendrocytes (Traiffort et al., 2016). Showing an increased amount of thinly myelinated axons within the lesion (the gold standard to demonstrate enhanced remyelination) would have further strengthened these findings. Interestingly, the decrease in oligodendrocyte apoptosis observed following Gpr17 inhibition in vitro was not seen in vivo, as revealed by the demyelination area and $\mathrm{CCl}^{+}$cell counts in the lesion at $3 \mathrm{~d}$ after lysolecithin injection. This discrepancy might be due to the different concentrations of lysolecithin in culture medium and nervous tissue after injection. It also suggests that this receptor pathway has more complex interactions with other signaling pathways in CNS tissue than in the simplified cell culture system.

Although the results of Ou et al. (2016), as summarized in Figure 1, draw a clear pathway by which Olig2 activation limits OPC differentiation and subsequently remyelination, previous works suggests that downstream signaling of Olig2 in this case is more complex than suggested by Figure 1 . For example, it has been demonstrated that overexpression of Olig2 caused precocious myelination during development and early remyelination following lysolecithin-induced demyelination in vivo partly by increasing migration and differentiation of OPCs (Wegener et al., 2015). In contrast, Ou et al. (2016) showed that overexpression 
of Gpr17, a transcriptional target of Olig2, reduced the viable oligodendrocyte population in vitro, and that the inhibition of Gpr17 enhanced developmental myelination and remyelination in vivo. The complexity of the Olig2 downstream signaling is further emphasized by findings from Mei et al. (2013); this study showed that the effect of Olig2 on myelination is stage specific: although it is necessary for differentiation of OPCs, it is a negative regulator for oligodendrocyte maturation and myelin formation. Together, these contradictory findings can be explained by the fact that Olig2 regulates the expression of many genes, and some of its effects may be beneficial for remyelination, whereas others (such as Gpr17 upregulation) are detrimental.

In addition to elucidating pathways underlying demyelination and remyelination, Ou et al. (2016) provide insight into the mode of action of lysolecithin as a demyelinating agent. Lysolecithin has been used for decades. Hall (1972) was the first to use it in the CNS to study demyelination followed by subsequent remyelination in vivo, and it has been used in vitro to study oligodendrocyte toxicity (Fressinaud et al., 1996). It has therefore become a well-established animal model to study demyelination/remyelination. It has generally been considered simply a detergent that disrupts the myelin sheath by producing micelles from the lipid bilayer (Triarhou and Herndon, 1986). This disturbance then induces microglial and macrophage responses (Triarhou and Herndon, 1985). Ou et al. (2016) now show that lysolecithin treatment of cultured oligodendrocytes for $12 \mathrm{~h}$ leads to apoptosis of these cells through activation of Olig2 and Gpr17, in the absence of microglia/macrophages, shedding new light on the mechanism through which lysolecithin causes demyelination. How lysolecithin mediates the upregulation of Olig2 at the beginning of insult remains unknown, however.

In conclusion, Ou et al. (2016) identify Gpr17 as a sensor and probable actor for lysolecithin-induced demyelination. These findings are important in three regards: (1) they suggest a novel mechanism by which oligodendrocytes undergo apoptosis following lysolecithin exposure; (2) given that it has previously been shown that Gpr17 is upregulated in MS plaques (Chen et al.,
2009), pharmacological inhibition of Gpr17 could be considered as a potential therapeutic approach for enhancing remyelination; and (3) the therapeutic inhibition of this pathway could be exploited in stroke and SCI as well because insufficient myelin repair is a challenge in these diseases (Plemel et al., 2014; Sozmen et al., 2016).

\section{References}

Ceruti S, Villa G, Genovese T, Mazzon E, Longhi R, Rosa P, Bramanti P, Cuzzocrea S, Abbracchio MP (2009) The P2Y-like receptor GPR17 as a sensor of damage and a new potential target in spinal cord injury. Brain 132: 2206-2218. CrossRef Medline

Chen Y, Wu H, Wang S, Koito H, Li J, Ye F, Hoang J, Escobar SS, Gow A, Arnett HA, Trapp BD, Karandikar NJ, Hsieh J, Lu QR (2009) The oligodendrocyte-specific $\mathrm{G}$ protein-coupled receptor GPR17 is a cell-intrinsic timer of myelination. Nat Neurosci 12:1398-1406. CrossRef Medline

Fressinaud C, Vallat JM, Pouplard-Barthelaix A (1996) Platelet-derived growth factor partly prevents chemically induced oligodendrocyte death and improves myelin-like membranes repair in vitro. Glia 16:40-50. CrossRef Medline

Fumagalli M, Daniele S, Lecca D, Lee PR, Parravicini C, Douglas Fields R, Rosa P, Antonucci F, Verderio C, Letizia Trincavelli M, Bramanti P, Martini C, Abbracchio MP (2011) Phenotypic changes, signaling pathway, and functional correlates of GPR17expressing neural precursor cells during oligodendrocyte differentiation. J Biol Chem 286:10593-10604. CrossRef Medline

Hall SM (1972) The effect of injections of lysophosphatidyl choline into white matter of the adult mouse spinal cord. J Cell Sci 10:535-546. Medline

Lassmann H (2013) Pathology and disease mechanisms in different stages of multiple sclerosis. J Neurol Sci 333:1-4. CrossRef Medline

Lecca D, Trincavelli ML, Gelosa P, Sironi L, Ciana P, Fumagalli M, Villa G, Verderio C, Grumelli C, Guerrini U, Tremoli E, Rosa P, Cuboni S, Martini C, Buffo A, Cimino M, Abbracchio MP (2008) The recently identified P2Y-like receptor GPR17 is a sensor of brain damage and a new target for brain repair. PLoS One 3:e3579. CrossRef Medline

Lu QR, Yuk D, Alberta JA, Zhu Z, Pawlitzky I, Chan J, Mcmahon AP, Stiles CD, Rowitch DH (2000) Sonic hedgehog-regulated oligodendrocyte lineage genes encoding bHLH proteins in the mammalian central nervous system. Neuron 25: 317-329. CrossRef Medline

Mahad DH, Trapp BD, Lassmann H (2015) Pathological mechanisms in progressive mul- tiple sclerosis. Lancet Neurol 14:183-193. CrossRef Medline

Mei F, Wang H, Liu S, Niu J, Wang L, He Y, Etxeberria A, Chan JR, Xiao L (2013) Stagespecific deletion of Olig2 conveys opposing functions on differentiation and maturation of oligodendrocytes. J Neurosci 33:84548462. CrossRef Medline

Ou Z, Sun Y, Lin L, You N, Liu X, Li H, Ma Y, Cao L, Han Y, Liu M, Deng Y, Yao L, Lu QR, Chen Y (2016) Olig2-targeted G-protein-coupled receptor Gpr17 regulates oligodendrocyte survival in response to lysolecithin-induced demyelination. J Neurosci 36:10560-10573. CrossRef Medline

Plemel JR, Keough MB, Duncan GJ, Sparling JS, Yong VW, Stys PK, Tetzlaff W (2014) Remyelination after spinal cord injury: is it a target for repair? Prog Neurobiol 117:5472. CrossRef Medline

Simon K, Hennen S, Merten N, Blättermann S, Gillard M, Kostenis E, Gomeza J (2016) The orphan G protein-coupled receptor GPR17 negatively regulates oligodendrocyte differentiation via Goi/o and its downstream effector molecules. J Biol Chem 291:705-718. CrossRef Medline

Sozmen EG, Rosenzweig S, Llorente IL, DiTullio DJ, Machnicki M, Vinters HV, Havton LA, Giger RJ, Hinman JD, Carmichael ST (2016) Nogo receptor blockade overcomes remyelination failure after white matter stroke and stimulates functional recovery in aged mice. Proc Natl Acad Sci U S A 113:E8453-E8462. CrossRef Medline

Traiffort E, Zakaria M, Laouarem Y, Ferent J (2016) Hedgehog: a key signaling in the development of the oligodendrocyte lineage. J Dev Biol 4:28.

Triarhou LC, Herndon RM (1985) Effect of macrophage inactivation on the neuropathology of lysolecithin-induced demyelination. Br J Exp Pathol 66:293-301. Medline

Triarhou LC, Herndon RM (1986) The effect of dexamethasone on L-alpha-lysophosphatidyl choline (lysolecithin)-induced demyelination of the rat spinal cord. Arch Neurol 43:121125. CrossRef Medline

Viganò F, Schneider S, Cimino M, Bonfanti E, Gelosa P, Sironi L, Abbracchio MP, Dimou L (2016) GPR17 expressing NG2-Glia: oligodendrocyte progenitors serving as a reserve pool after injury. Glia 64:287-299. CrossRef Medline

Wegener A, Deboux C, Bachelin C, Frah M, Kerninon C, Seilhean D, Weider M, Wegner M, Nait-Oumesmar B (2015) Gain of Olig2 function in oligodendrocyte progenitors promotes remyelination. Brain 138: 120-135. CrossRef Medline

Zhou Q, Wang S, Anderson DJ (2000) Identification of a novel family of oligodendrocyte lineage-specific basic helix-loop-helix transcription factors. Neuron 25:331-343. CrossRef Medline 